\title{
The impact of air quality on tourism: a systematic literature review
}

\author{
Celeste Eusébio, Maria João Carneiro, Mara Madaleno, Margarita Robaina, Vítor Rodrigues, \\ Michael Russo, Hélder Relvas, Carla Gama, Myriam Lopes, Vania Seixas, Carlos Borrego \\ and Alexandra Monteiro
}

\begin{abstract}
Purpose - Tourism may have important positive and negative economic, socio-cultural and environmental impacts. However, cultural and natural resources are also the base to the development of competitive destinations and changes in these resources can have an important impact on tourism development. Despite the considerable literature regarding the impacts of tourism, a limited number of studies examine the impact of the environment on tourism, specifically the impact of air quality (AQ). Therefore, this paper aims to review what is known about the impact of $A Q$ on tourism demand, analysing the different methods and approaches used, as well as the results obtained.

Design/methodology/approach - A systematic literature review method was used to examine the state of the art in this topic and identify research gaps and new research directions. Only 26 papers were identified that examine the impact of $A Q$ on tourism demand.

Findings - The majority of the studies were carried out in China and investigate the impact of $A Q$ on tourism from the perspective of tourism demand. Both global (tourism demand) and individual (tourist perceptions) approaches have been used to investigate the impact of $A Q$ on tourism.

Originality/value - This is the first systematic literature review on the impact of outdoor $A Q$ on tourism demand. Moreover, this paper analyses the methods and approaches that have been used in the literature to examine the impact of outdoor $A Q$ on tourism demand. The paper ends with a discussion on the identified research gaps concerning the influence of $A Q$ on tourism development.
\end{abstract}

Keywords Tourism, Air quality, Impact, Air pollution, Systematic literature review

Paper type Research paper

\section{Introduction}

In the present era, one of the major motivations for travelling is to avoid the usual environment and seek a site with a pleasant location for releasing psychological stress and pressure (Ritchie and Crouch, 2003). Therefore, environmental quality must be taken into account as an important factor in the decision-making process of potential tourists, as it can have a significant effect on the competitiveness of tourism destinations (Zhang et al., 2015; Becken et al., 2017). However, the environment in some large tourism destination countries such as Egypt, China and India, is deteriorating with the progressive urbanization and industrialization. Beyond the "traditional" environmental problems such as garbage disposal and water pollution, the problem of haze pollution has risen in recent years, and air quality (AQ) has become a universal concern (Chen et al., 2017), now being incorporated into the wider category of environmental quality.

Ambient $A Q$ should attract more academic attention than thermal comfort and the aesthetic dimension of the physical environment, as $A Q$ is closely related to health risks (Costa et al., 2014). However, the existing literature places relatively low attention on the effects of $A Q$ on tourism demand and the competitiveness of tourism destinations. Overall, the impacts of
Celeste Eusébio, Maria João Carneiro, Mara Madaleno, Margarita Robaina and Vítor Rodrigues are all based at GOVCOPP, Department of Economics, Management, Industrial Engineering and Tourism, University of Aveiro, Aveiro, Portugal. Michael Russo, Hélder Relvas, Carla Gama, Myriam Lopes, Vânia Seixas, Carlos Borrego and Alexandra Monteiro are all based at CESAM, Department of Environment and Planning, University of Aveiro, Aveiro, Portugal.

Received 6 June 2019 Revised 8 November 2019 Accepted 23 January 2020

(c) Celeste Eusébio, Maria João Carneiro, Mara Madaleno, Margarita Robaina, Vítor Rodrigues, Michael Russo, Hélder Relvas, Carla Gama, Myriam Lopes, Vania Seixas, Carlos Borrego and Alexandra Monteiro Published in Journal of Tourism Futures. Published by Emerald Publishing Limited. This article is published under the Creative Commons Attribution (CC BY 4.0) license. Anyone may reproduce, distribute, translate and create derivative works of this article (for both commercial and non-commercial purposes), subject to full attribution to the original publication and authors. The full terms of this license may be seen at http:// creativecommons.org/ licences/by/4.0/legalcode 
environmental and climate change issues on tourism have previously been discussed in several studies but few of them have focussed directly on the impacts of air pollution on the competitiveness of a tourism destination (Saenz-de-Miera and Rosselló, 2013; Rossello-Nadal, 2014; Sajjad et al., 2014). AQ also pertains to physical comfort, which is crucial to tourist experiences and has become a severe concern for human health. Medical evidence suggests that short and long-term exposures to ambient air pollution can engender a wide variety of acute and chronic health problems (Seaton et al., 1995; WHO, 2017). Moreover, AQ also affects aesthetic enjoyment, with people's perception of reduced visibility, which is affected by the presence of particles and haze, which is being increasingly researched (Rizzi et al., 2014).

The objective of this paper is to review what is known and has been published, about the impact of outdoor $A Q$ on tourism demand, using a systematic literature review method. To date, there is no literature review study on this topic. It is of note that the impact of tourism on $A Q$ was also not addressed. This literature review aims to identify the geographical context, research methodologies used, researched subjects of the papers and the findings on the impact of $A Q$ on tourism. This approach was adopted to provide contributions to guide future research, regarding which models should be used and what kind of data needs to be collected.

The paper is organized in various sections. In Section 2, the methodology used to select and analyse the papers is presented. In Section 3, the findings are reported, specifically the distribution of papers over time, among journals, subject areas, authorship and citations, the geographical contexts of the studies and the research methods used (data collection and data analysis methods), as well as the key results found. Finally, in Section 4, the main conclusions are summarized, research gaps are identified and some research questions are proposed to overcome these gaps.

\section{Methodology}

Several types of methodologies have been used in previous articles to conduct a literature review (e.g. systematic literature review, structured literature review, bibliometric analysis and systematic literature network analysis) (Centobelli and Ndou, 2019; Comerio and Strozzi, 2019). The differences among these methodologies are mainly related to the research protocol used. In this paper, a systematic literature review is applied and the research protocol used encompasses two stages. First, a protocol was defined and put into practice to select the articles that will be analysed. Second, a content analysis of the articles selected was undertaken.

\subsection{Articles selection}

The protocol used to select the papers is reported in Figure 1.

As presented in Figure 1, the identification of the studies was carried out through a search on the Scopus database during January 2019, using the following search code - ("AQ" or "atmospheric emissions" or "air pollutants") and ("tourism" or "visitor" or "tourist") - in the article title, abstract and keywords without any restriction of time or subject. This database has been used in several previous studies (Centobelli and Ndou, 2019; Comerio and Strozzi, 2019; Dann et al., 2019) and is one of the largest databases of peer-reviewed literature (scientific journals, books and conference proceedings). A total of 488 records were obtained. Further, to include both scientific literature and "grey" literature, articles, reviews, articles in press and conference proceedings were selected. As a consequence of this first screening, the sample of records reduced to 383. Further, only documents written in English were selected. Papers written in other languages were excluded, given the complexities associated with translation. Based on this screening, 26 records were excluded.

Manual screening of the abstract titles and the abstracts of the 357 records was carried out by two authors (one specialized in $A Q$ and the other in tourism) to verify if each paper was 


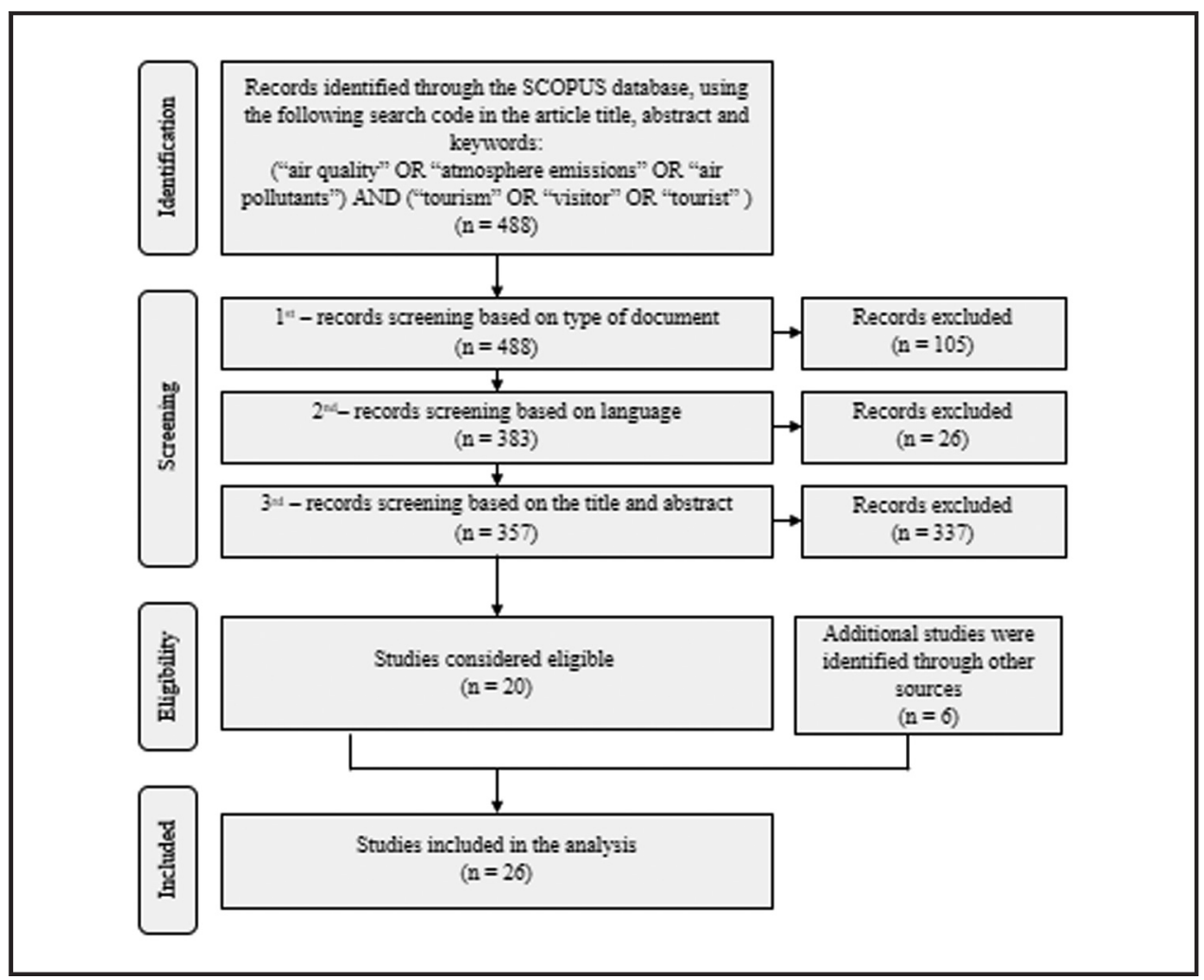

relevant to be included in this research. When the title and the abstract were not conclusive, the whole article was analysed. Concerning the inclusion criteria, it was decided to include both conceptual and empirical studies (qualitative and quantitative), where the influence of outdoor $\mathrm{AQ}$ on tourism demand of a tourism destination was analysed. Therefore, papers regarding the environmental impact of tourism on $A Q$ and studies concerning indoor $A Q$ of tourism attractions and facilities were excluded from this systematic literature review. A great number of documents only mention the topics of $A Q$ and tourism in a superficial way, without an analysis of the impact of outdoor $\mathrm{AQ}$ on tourism demand. Consequently, only 20 papers were selected. To increase the sample of papers selected, two complementary searches were carried out on the Google Scholar database and Online Knowledge Library (b-on). From these analyses, only one additional paper was added. Further, the references of the 21 papers identified were analysed and 5 more papers were included in the sample. Consequently, a total of 26 papers were selected to be analysed in the second stage of this systematic literature review. This reduced number of papers clearly shows that this topic has been almost neglected in the literature, despite the great increase that the tourism industry has registered in the past few years and the increase in well-being and health concerns.

\subsection{Articles analysis}

The articles selected in the previous stage were analysed using two steps. First, a descriptive analysis of the following aspects was carried out:

- The distribution over time;

- Distribution by journal, scientific area and authorship; and

- The distribution by the geographical context where the study was conducted. 
As both empirical and theoretical studies were found, in a second stage, a content analysis of the empirical papers was developed to identify as follows:

- The research methods (data collection and data analysis methods);

- The dimensions of $A Q$ and tourism demand investigated; and

- The results obtained concerning the impact of outdoor $A Q$ on the dimensions of tourism demand analysed.

This content analysis was complemented with an investigation of word frequencies (in title, abstract and keywords), using the Nvivo software, to identify, through word clouds, the terms most frequently used in this research field.

\section{Findings}

\subsection{Distribution of the papers over time}

A total of 26 papers were analysed. There seems to be a growing interest on the impact of outdoor $\mathrm{AQ}$ on tourism demand among researchers, as most of these papers were published in the past decade (88 per cent), mainly in 2017 and 2018 (12 and 42 per cent of the total set of papers were published in these years, respectively) (Figure 2).

\subsection{Journals, authorship and citations}

There is a great variety among the authors of these papers. Almost all (98 per cent) wrote one paper and only Rob Law is the author of two. The papers are published in journals and conference proceedings of several areas, which reveals the relevance of this topic to different fields. However, there is a higher prevalence of papers in journals or proceedings from the field of "tourism, leisure and hospitality management" (38 per cent), with a notable contribution of "environmental science" (19 per cent), also having some papers published in journals or proceedings in the areas of "geography, planning and development" (8 per cent) and "health" or "medicine" ( 8 per cent) (Table I). It is important to notice that journals or proceedings can be related to more than one field, for example, environment and health. Papers have, on average, 7.2 citations in Scopus and 11.0 citations in Google Scholar. However, there is a high variation regarding citations, with many of the most recent papers

\section{Figure 2 Number of papers published by year of publication}

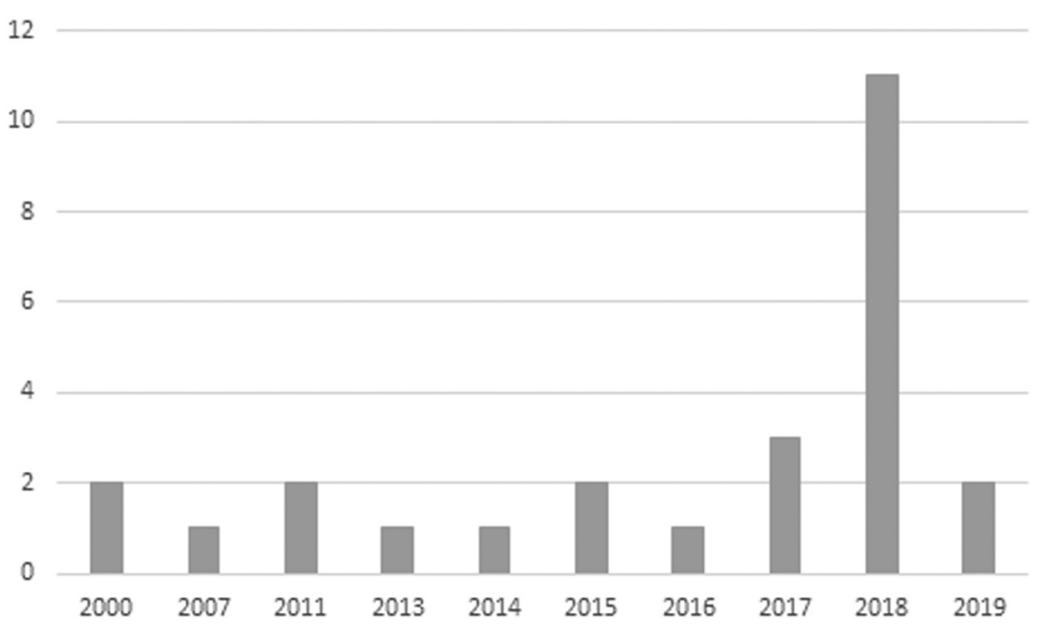


(representing 19 per cent of the total) not yet having any citations in Scopus or Google Scholar, while 23 per cent have more than 20 citations in Scopus or in Google Scholar (Table I).

\subsection{Geographical context}

In terms of geographical areas, Figure 3 reveals that the spatial distribution of the published work addressing the impact of $A Q$ on tourism is mainly focussed over the China and Southeast Asia regions.

China emerges as the country where most studies were conducted (about 42 per cent of the total), mainly in its capital (Beijing) with five specific studies focussed on this city (and not included in the six studies for China as a country shown in Figure 2). When other Asian countries are considered, the number of studies carried out in this region represents 58 per cent of the total studies analysed. Moreover, 16 per cent of the published studies were undertaken in the USA. A limited number of studies were conducted in European countries.

\subsection{Most frequently used terms}

The word clouds were generated through the qualitative analysis software NVivo 12, which allowed us to develop a word frequency query. To do so, this task separately analysed the word frequency in specific items of the mentioned papers, namely, the title, keywords and abstract. By default, the software automatically excludes the so-called "stop words", which refer to conjunctions and/or prepositions and similar, which helped to substantially reduce the number of meaningless words. In each case, the words with a frequency equal to "1" were excluded, mainly because they may not be meaningful to the study objectives. Additionally, the following expressions, matching with the search terms used in the initial protocol, were also excluded: "AQ", "atmospheric emissions", "air pollutants", "tourism", "visitor" and "tourist". To obtain more accurate results, the words were grouped according to the option "stemmed words", which groups similar words such as "significant" and "significantly".

Originally, the analysis generated 930 words in the case of the abstracts, 142 for the titles and 118 for keywords. By applying the above-mentioned filter, the final result was a total of 432, 31 and 38 words, respectively. Based on each list of frequencies, the software created the following word clouds (Figure 4). Focussing on the top five of the most significant words, and as observed in Figure 4, only the expressions "pollution" and "environmental" are common in the analysed lists. The words "impact", "China" and "perceptions" also appear with high frequency in, at least, two of the three lists of frequencies and "parks" or "haze", reflecting the common topics between the several considered studies.

\subsection{Research methods}

Most papers selected for this systematic review include empirical studies, only one is a literature review (Zajchowski et al., 2018). The literature review carried out by Zajchowski et al. (2018) differs from the one in the present paper, as it only focusses on the social and psychological effects of degraded AQ in and around parks and protected areas, and only analyses papers published in journals. In contrast, the analysis carried out in the present paper focussed, as already mentioned, on destinations, excluding specific attractions, but encompassed a wider range of documents, including papers published in conference proceedings. Only three papers - Hill et al. (2000), Keiser et al. (2018) and Zhang et al. (2015) - are cited in the two literature reviews.

In this section, the methods used in the papers that include an empirical study to collect and analyse the data are described. It was considered useful to include a summary of the methodologies adopted to examine the influence of outdoor $A Q$ on tourism. This would be 
Table I

Information on the publication, authorship and citations (continues)

Authors (year of publication)

Anaman and Looi (2000)

Hill et al. (2000)

Law and Cheung
(2009)

Bohm and Pfister (2011)

Hipp and

Ogunseitan (2011)

Poudyal et al. (2013)

Sajjad et al. (2014)

Nejati et al. (2015)

Sato et al. (2016)

\section{Becken et al. (2017) $\begin{array}{ll}\text { Study } \\ \text { Urban }\end{array}$}

Sustainable Tourism

Zhang et al. (2015) Tourists' Perception of Haze Pollution and the Potential Impacts on Travel: Reshaping the Features of Tourism Seasonality in Beijing, China

Effect of Short-Term Exposure to High Particulate Levels on Cough Reflex Sensitivity in Healthy Tourists: A Pilot

$\begin{array}{ll}\text { Becken et al. (2017) } & \text { Urban air pollution in } \\ & \text { China: destination image }\end{array}$ and risk perceptions

Deng et al. (2017) Evaluating impact of air pollution on China's inbound tourism industry: a spatial econometric approach

$\begin{array}{ll}\begin{array}{l}\text { Journal or } \\ \text { proceedings }\end{array} & \begin{array}{l}\text { Domain of the journal or } \\ \text { proceedings }\end{array} \\ \begin{array}{ll}\text { Economic Analysis } & \text { Economics, econometrics and } \\ \text { and Policy } & \text { finance: economics and } \\ \text { econometrics }\end{array}\end{array}$

USDA Forest a)

a)

8

Proceedings

Journal of

Sustainable

Tourism

Scandinavian

Journal of

Hospitality and

Tourism

Journal of

Environmental

Psychology

Tourism Economics

Business, management and accounting: tourism, leisure and hospitality management

Business, management and and hospitality management Business, management and accounting: tourism, leisure and hospitality management

Psychology: applied

30

Psychology

Environmental

Environmental science:

25

Science and pollution

Pollution Research

e-Review of

Business, management and and hospitality management

Sustainability

Social sciences: geography, planning and development

28

Open Respiratory

Medicine: Pulmonary and

2

4

Medicine Journal Respiratory Medicine

\section{Journal of}

Sustainable

Tourism

Business, management and accounting: tourism, leisure and hospitality management Asia Pacific Journal Business, management and of Tourism accounting: tourism, leisure and hospitality management 


\section{Table I}

Authors (year of publication)

Agarwal et al. (2018)

Jun-Hui (2018)

Keiser et al. (2018)

Pant et al. (2018)

Peng and Xiao (2018)

Saura et al. (2018)

Wang et al. (2018)

Wu et al. (2018)

Zajchowski et al. (2018)

Zhou et al. (2018)

Zhu (2018)

Liu et al. (2019)

Yan et al. (2019)

Title of the paper

Blessing in disguise? Environmental shocks and performance enhancement Research on the Tourists' Type and Behavior based on the Fog and Haze Perception: Taking Xi'an as a Case

Air pollution and visitation at US national parks

Exposure to air pollutants in Vietnam: Assessing potential risk for tourists How does smog influence domestic tourism in China? A case study of Beijing

Attitudes Expressed in Online Comments about Environmental Factors in the Tourism Sector: An Exploratory Study

Effect of air quality in the place of origin on outbound tourism demand: Disposable income as a moderator Chinese behind the wheel: factors affecting their satisfaction with international self-drive holidays

Air quality and the visitor experience in parks and protected areas

Air quality and inbound tourism in China

Analysis on the Impact of haze on Beijing Residents' Traveling Intention and DecisionMaking Tourism Development, Environment and Policies: Differences between Domestic and International Tourists

Exploring the effect of air pollution on social activity in China using geotagged social media check-in data $\begin{array}{ll}\text { Journal or } & \begin{array}{l}\text { Domain of the journal or } \\ \text { proceedings }\end{array} \\ \text { proceedings }\end{array}$

Citations in SCOPUS

Citations in

proceedings

a)

a)

a)

E3S Web of

Conferences 53

Environmental science:

0 general environmental science

Science Advances

Multidisciplinary

Journal of

Environmental

Sciences

Environmental Science: general environmental science

Asia Pacific Journal Business, management and accounting: tourism, leisure and hospitality management

Research

Environmental science: health,

Journal of

Environmental

Research and

Public Health

Tourism

Management

Business, management and and hospitality management

Business, management and

Destination

Marketing and

Management
Tourism

Geographies

Tourism Analysis

IOP Conference

Series: Materials

Science and

Engineering

Sustainability

Social sciences: geography,

Business, management and and hospitality management Business, management and accounting: tourism, leisure and hospitality management Engineering: general engineering

.

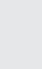

(1)

$$
\text { planning and development }
$$$$
\text { Social sciences: urban studies }
$$

4
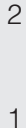

4

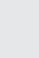

(1)

Note: a) No information is provided in SCOPUS or in Google Scholars 
Table II Type of data, collection method and sources

\begin{tabular}{|c|c|c|}
\hline Type of data & $\begin{array}{l}\text { Type of data } \\
\text { collection method/ } \\
\text { sources }\end{array}$ & Authors/year \\
\hline \multirow[t]{3}{*}{ Primary data } & Questionnaires & $\begin{array}{l}\text { Becken et al. (2017), Bohm and Pfister (2011), Hill et al. (2000), Hipp and } \\
\text { Ogunseitan (2011), Jun-hui (2018), Law and Cheung (2009), Nejati et al. (2015), } \\
\text { Peng and Xiao (2018), Wu et al. (2018), Zhang et al. (2015) and Zhu (2018) }\end{array}$ \\
\hline & Interviews & Wu et al. (2018) \\
\hline & Experiments & Pant et al. (2018) and Sato et al. (2016) \\
\hline \multirow[t]{2}{*}{ Secondary data } & $\begin{array}{l}\text { Quantitative data } \\
\text { provided by } \\
\text { national or } \\
\text { international } \\
\text { sources }\end{array}$ & $\begin{array}{l}\text { Agarwal et al. (2018), Anaman and Looi (2000), Chen et al. (2017), Deng et al. } \\
\text { (2017), Hipp and Ogunseitan (2011), Jun-hui (2018), Keiser et al. (2018), Liu } \\
\text { et al. (2019), Pant et al. (2018), Poudyal et al. (2013), Sajjad et al. (2014), Wang } \\
\text { et al. (2018), Yan et al. (2019) and Zhou et al. (2018) }\end{array}$ \\
\hline & Online reviews & Agarwal et al. (2018) and Saura et al. (2018) \\
\hline
\end{tabular}

Table III Methods of data analysis

\begin{tabular}{|c|c|c|}
\hline Type of methods & Description of the method & Authors/year \\
\hline Qualitative & Content analysis & Saura et al. (2018) and Wu et al. (2018) \\
\hline \multirow[t]{18}{*}{ Quantitative } & Descriptive statistics & $\begin{array}{l}\text { Agarwal et al. (2018), Anaman and Looi (2000), Becken et al. (2017), } \\
\text { Bohm and Pfister (2011), Hill et al. (2000), Hipp and Ogunseitan } \\
\text { (2011), Jun-hui (2018), Law and Cheung (2009), Liu et al. (2019), Nejati } \\
\text { et al. (2015), Pant et al. (2018), Poudyal et al. (2013), Sato et al. (2016), } \\
\text { Saura et al. (2018), Wang et al. (2018), Wu et al. (2018), Yan et al. } \\
\text { (2019), Zhang et al. (2015), Zhou et al. (2018) and Zhu (2018) }\end{array}$ \\
\hline & Correlations & $\begin{array}{l}\text { Hipp and Ogunseitan (2011), Pant et al. (2018), Saura et al. (2018) and } \\
\text { Zhang et al. (2015) }\end{array}$ \\
\hline & $\chi^{2}$ tests & Zhu (2018) \\
\hline & t-tests & $\begin{array}{l}\text { Hipp and Ogunseitan (2011), Law and Cheung (2009), Sato et al. } \\
\text { (2016) and Saura et al. (2018) }\end{array}$ \\
\hline & $\begin{array}{l}\text { ANOVA; multivariate analysis of } \\
\text { variance }\end{array}$ & $\begin{array}{l}\text { Becken et al. (2017), Bohm and Pfister (2011), Law and Cheung (2009) } \\
\text { and Sato et al. (2016) }\end{array}$ \\
\hline & $\begin{array}{l}\text { Reliability analysis (Cronbach's } \\
\text { alpha) }\end{array}$ & Wu et al. (2018) \\
\hline & $\begin{array}{l}\text { Exploratory factor analyses; and } \\
\text { confirmatory factor analyses }\end{array}$ & Becken et al. (2017), Peng and Xiao (2018) and Zhu (2018) \\
\hline & Linear regression analyses & $\begin{array}{l}\text { Agarwal et al. (2018), Anaman and Looi (2000), Keiser et al. (2018), } \\
\text { Wang et al. (2018) and Wu et al. (2018) }\end{array}$ \\
\hline & Logit models & Agarwal et al. (2018) and Hipp and Ogunseitan (2011) \\
\hline & Poisson regression & Anaman and Looi (2000) \\
\hline & Spatial models & Deng et al. (2017) \\
\hline & Structural equation models & Becken et al. (2017), Nejati et al. (2015) and Peng and Xiao (2018) \\
\hline & Panel data fixed effects model & $\begin{array}{l}\text { Agarwal et al. (2018), Liu et al. (2019), Wang et al. (2018), Yan et al. } \\
\text { (2019) and Zhou et al. (2018) }\end{array}$ \\
\hline & $\begin{array}{l}\text { Corrected least squares dummy } \\
\text { variable model }\end{array}$ & Zhou et al. (2018) \\
\hline & Markov regime-switching model & Chen et al. (2017) \\
\hline & VAR model & Sajjad et al. (2014) \\
\hline & Contingency models & Hill et al. (2000) \\
\hline & Polynomial distributed lag model & Poudyal et al. (2013) \\
\hline
\end{tabular}

helpful in future research to identify potential methodologies that may be used to assess this influence.

3.5.1 Type of data and data collection methods. In terms of the type of data used, the observed sample of articles reviewed is well distributed between primary and secondary data (Table II). A total of 56 per cent of our sample used primary data. From these, 
11 articles use questionnaires to explore the relationship between $A Q$ and tourism. Only one study relies on interviews directed to tourists and two rely on experiments to extract primary data. The data sources used to collect secondary data correspond to diverse sources, which can be divided into quantitative data and online reviews. In total, 14 studies collect data from quantitative national and international sources to explore the AQ-tourism relationship and only two of the reviewed articles consider tourists' online reviews as secondary source data. Moreover, some studies simultaneously use primary and secondary data sources to drive reliable conclusions, merging experiments or questionnaires with secondary data. At least Hipp and Ogunseitan (2011), Jun-hui (2018) and Pant et al. (2018) simultaneously use primary and secondary data. To study visitors' perceptions of $A Q$ or to infer about the impact of air pollution on tourism, the joint use of questionnaires and evaluations collected from well-known travelling opinion surveys (such as in TripAdvisor; Saura et al., 2018) can be particularly efficient and practical.

3.5.2 Data analysis methods. Table IV presents a summary of the methodologies used by the authors considered in this literature review regarding the impacts of $A Q$ on tourism. Most of the studies analysed use a quantitative analysis (92 per cent), while only 8 per cent (two studies) rely on qualitative analysis.

In terms of econometric methodologies, simple data analysis is the preferred method considering that it is complex/difficult to collect a long time series of data using questionnaires to build hypotheses and then test them. Even so, the content analysis could be another alternative when using qualitative data, but authors have only recently started using it (Wu et al., 2018; Saura et al., 2018). When using quantitative data, Table IV shows that the most applied methods are those of ANOVA, linear regression analysis and panel data models. Simple descriptive statistics are used in 80 per cent of the studies analysed, where correlation analysis and $t$-tests are also commonly applied to explore data properties. The use of $\chi^{2}$ tests and reliability analysis is less common.

More complex econometric models are used when authors use quantitative secondary data (Tables II and III). These models allow having both a clearer picture of the quantitative

\section{Table IV Dimensions of $\mathrm{AQ}$}

\begin{tabular}{lll}
\hline Type of study & Dimensions AQ analysed & Authors \\
\hline $\begin{array}{l}\text { Impact on } \\
\text { individual visitors }\end{array}$ & $\begin{array}{l}\text { Perceptions of environmental risks } \\
\text { Perceptions of AQ }\end{array}$ & $\begin{array}{l}\text { Becken et al. (2017) } \\
\text { Bohm and Pfister (2011), Hipp and Ogunseitan (2011), Law } \\
\text { and Cheung (2009), Nejati et al. (2015) and Wu et al. (2018) } \\
\text { Hill et al. (2000), Jun-hui (2018), Wu et al. (2018), Zhang } \\
\text { et al. (2015) and Zhu (2018) }\end{array}$ \\
& Perceptions of haze pollution & Saura et al. (2018) \\
& Perceptions of factors related to & \\
atmospheric contaminations & Bohm and Pfister (2011) and Hipp and Ogunseitan (2011) \\
& Perceptions of ozone depletion & Agarwal et al. (2018) \\
& PSl, days of haze and visibility & Jun-hui (2018) \\
& Perceptions of fog & Peng and Xiao (2018) \\
Perceptions of smog & Pant et al. (2018) and Sato et al. (2016) \\
PM & Pant et al. (2018) \\
Black carbon & Sajjad et al. (2014) \\
Impact on global & Chen et al. (2017), Yan et al (2019) and Zhou et al. (2018) \\
tourism demand & Air pollution index & Wang et al. (2018) and Yan et al (2019) \\
& AQ index & Anaman and Looi (2000) \\
& haze-related air pollution & Deng et al. (2017) \\
Industrial waste gas emission & Keiser et al. (2018) \\
& Ozone pollution & Liu et al. (2019) and Sajjad et al. (2014) \\
& Carbon dioxide emissions & Liu et al. (2019) \\
& PM concentrations & Poudyal et al. (2013) \\
& Visibility &
\end{tabular}




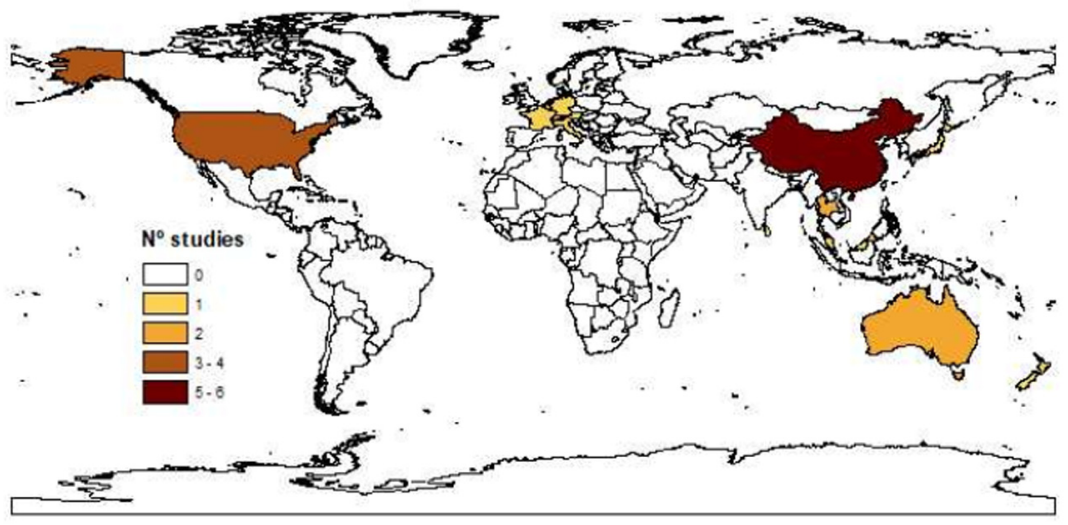

Figure 4 Word frequency represented by word clouds according to abstracts, titles and keywords
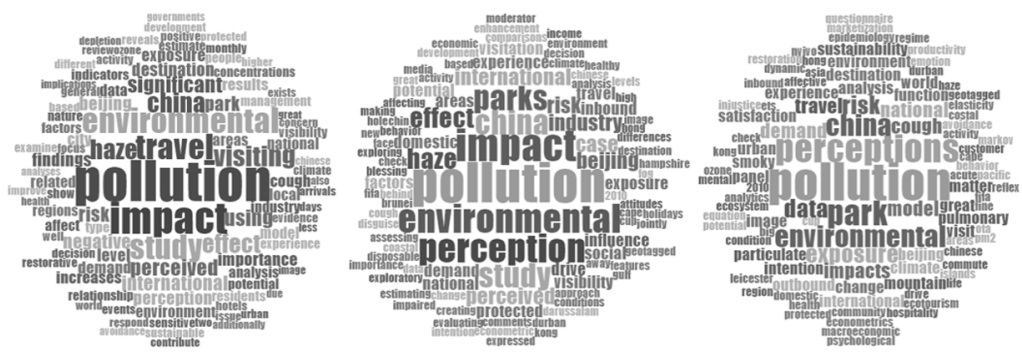

impact of $A Q$ on tourism and economic growth, as well as development at national and regional levels. The analysis suggests that using secondary data panel models and time series models (like VAR) allows for a more complete analysis of the relationship between $A Q$ and tourism. Content analysis, which has not been used, can be used together with other methods to perform a more in-depth analysis of the influence of $A Q$ on the tourism demand.

Logit models, Poisson regressions, spatial models, structural equation models, corrected least squares dummy variable models, Markov regime-switching, contingency and polynomial distributed lag models are less commonly used among authors. Therefore, a lot of work remains to be done in econometric terms and more suitable models are necessary to examine the interaction between $\mathrm{AQ}$ and tourism at both national and regional analysis. For example, considering available monthly data, it will be possible to apply models able to capture simultaneous interactions between $A Q$ variables and tourism variables, such as a vector autoregressive model (VAR) used by Sajjad et al. (2014). VAR is a stochastic process model used to capture the linear interdependencies among multiple time series, where all variables are simultaneously considered to be endogenous and exogenous. This model does not require as much knowledge about the forces influencing a variable as structural models with simultaneous equations; the only prior knowledge required is a list of variables, which can be hypothesized to affect each other intertemporally. Additionally, when considering regional or municipalities' analysis, panel VAR models are also suitable and possible to use. Finally, they allow testing dynamic data correlations by using, for 
example, Granger causality. These models are particularly suited to address issues that are currently at the centre stage of discussions in academics and in the policy arena, as they are able to:

- capture both static and dynamic interdependencies;

- treat the links across units in an unrestricted fashion;

- easily incorporate time variations in the coefficients and in the variance of the shocks;

- account for cross sectional dynamic heterogeneities; and

- use Granger causality and capture more complex correlation analysis.

Moreover, more qualitative studies should be carried out in this field to examine the influence of $A Q$ on the behaviour and experiences of tourists. Table IV evidences the limitations, thus, far in terms of methodology analysis and provides valuable future research directions.

\subsection{Variables used}

3.6.1 Dimensions of air quality. The variables used in the various studies to measure $A Q$ and its impact on tourism differ, essentially, between studies that examine the impact of $A Q$ on visitors and studies that analyse the impact of $A Q$ on global tourism demand. In the first group, a great number of studies use the perception of $A Q$ and the perception of haze pollution (Table IV). In a smaller number of studies, visitor perception of the environmental risks, atmospheric contaminations, ozone depletion, fog and smog are analysed. Additionally, other studies use measurements of variables related to $A Q$ rather than visitor perception such as the pollution standard index (PSI), days of haze, visibility, particulate matter (PM) and black carbon.

Articles that analyse the impacts of $A Q$ on global tourism demand are no longer based on perception but quantitative $A Q$ variables. Most studies are based on indices of air pollution (or $\mathrm{AQ}$ ). There is another subset of studies that are based on emission variables (e.g. $\mathrm{CO}_{2}$, waste gases, methane, nitrous oxide and ozone). Moreover, there is a dispersion of studies that use other variables such as visibility, PM concentrations and haze.

3.6.2 Dimensions of tourism demand. The impact of $A Q$ on tourism demand has been analysed through several approaches. Therefore, the analysed articles were categorized into two groups according to the impact of $A Q$ on:

1. Individual visitors.

2. Global tourism demand.

In the first group, most of the studies examine the travel intention and destination choice. Moreover, the effect of $\mathrm{AQ}$ on tourism has also been analysed through the well-being and quality of life (QOL) variables (including physical and psychological health). A limited number of studies examined the impact of $A Q$ on tourism experience, destination image, visitors' satisfaction and type of activities carried out during a trip. In the second group, the studies focus on global tourism demand, mainly on the size of tourism flows (e.g. tourist arrivals, number of visitors, departures, international tourism receipts and expenditures) (Table V). However, several dimensions of tourism demand have been neglected in these studies such as the impact of $A Q$ on destination competitiveness, emotions, memorability and post-travel behaviours.

\subsection{Impact of air quality on tourism}

Because of the limited number of studies and due to the diversity of dimensions of $A Q$ and tourism demand analysed, it is complex to draw many conclusions regarding the impact of 
Table V Dimension of tourism demand

Dimensions of tourism affected

Type of study by $A Q \quad$ Authors

\begin{tabular}{|c|c|c|}
\hline \multirow[t]{4}{*}{$\begin{array}{l}\text { Impact on } \\
\text { individual visitors }\end{array}$} & $\begin{array}{l}\text { Travel behaviour, travel } \\
\text { intention and destination choice }\end{array}$ & $\begin{array}{l}\text { Becken et al. (2017), Bohm and Pfister (2011), Hill et al. (2000), } \\
\text { Jun-hui (2018), Law and Cheung (2009), Peng and Xiao (2018), } \\
\text { Zhang et al. (2015) and Zhu (2018) }\end{array}$ \\
\hline & Well-being and QOL & $\begin{array}{l}\text { Bohm and Pfister (2011), Hipp and Ogunseitan (2011), Pant } \\
\text { et al. (2018), Peng and Xiao (2018) and Sato et al. (2016) }\end{array}$ \\
\hline & Visitors' satisfaction & $\begin{array}{l}\text { Agarwal et al. (2018), Peng and Xiao (2018), Saura et al. (2018) } \\
\text { and Wu et al. (2018) }\end{array}$ \\
\hline & Destination image & Becken et al. (2017), Hill et al. (2000) and Peng and Xiao (2018) \\
\hline \multirow[t]{5}{*}{$\begin{array}{l}\text { Impact on global } \\
\text { tourism demand }\end{array}$} & Tourist arrivals & $\begin{array}{l}\text { Anaman and Looi (2000), Deng et al. (2017) and Zhou et al. } \\
\text { (2018) }\end{array}$ \\
\hline & Number of visitors & $\begin{array}{l}\text { Chen et al. (2017), Keiser et al. (2018), Liu et al. (2019) and } \\
\text { Poudyal et al. (2013) }\end{array}$ \\
\hline & $\begin{array}{l}\text { International tourism receipts } \\
\text { and expenditures }\end{array}$ & Sajjad et al. (2014) \\
\hline & Urban activities & Yan et al (2019) \\
\hline & Outbound tourism demand & Wang et al. (2018) \\
\hline
\end{tabular}

AQ on tourism demand. However, some trends may be highlighted. Therefore, the most important results obtained in the papers reviewed in this article will be presented, categorized into two groups (Table V) as follows:

1. Papers that analyse the impact of $A Q$ on individual visitors.

2. Papers that examine the impact of $A Q$ on global tourism demand.

3.7.1 Impact on individual visitors. Results regarding the impact of $A Q$ on individual visitors will be presented according to the dimensions of tourism demand considered in the studies:

- Travel behaviour, travel intention and destination choice;

- Well-being and QOL;

- Visitors' satisfaction; and

- Destination image.

3.7.1.1 Impact on travel behaviour, travel intention and destination choice. A deep analysis of the results reveals that good $A Q$ is likely to have a positive influence on travel behaviour, travel intention and destination choice (Bohm and Pfister, 2011; Becken et al., 2017; Hill et al., 2000; Jun-hui, 2018; Law and Cheung, 2009; Zhang et al., 2015; Zhu, 2018). This corroborates part of the findings of the literature review undertaken by Zajchowski et al. (2018) on the effects of good AQ on human behaviour. However, the variables representing $A Q$, the methodologies adopted and the tourism markets and destinations considered, vary across the studies. Zhu (2018), Zhang et al. (2015) and Hill et al. (2000) analyse haze effects on tourism in Beijing, while Zhu (2018) examines how the haze affects the travel wishes and decisions of Beijing residents. The results show that for the majority of the residents, hazy weather has an impact on their willingness to travel and means of travel. More than 80 per cent of the respondents are not satisfied with travelling during fog and haze days. Moreover, differences in terms of age were identified, with young people (under the age of 20) being more reluctant to travel on haze days. Zhang et al. (2015) also analyse the potential impacts of haze pollution on the tourism industry of Beijing, through a questionnaire applied to potential tourists of this tourism destination. The results obtained reveal that haze pollution affects tourist choice of destinations and departure time. 
Differences are noticed among visitors with different travel purposes, with visitors travelling for sightseeing and leisure revealing a much higher concern regarding haze pollution than those travelling for business or visiting friends and relatives. Leading to visibility conditions that depend on haze affecting the likelihood of visiting the destinations in the future. Hill et al. (2000) analysed this topic for the White Mountain National Forest, NH (USA) and concluded that as visibility decreases, the probability of accepting visibility conditions tends to decrease and also that potential visitors planning a visit to the White Mountains in the future would be less likely to visit this protected area if the visibility conditions got worse. Finally, Jun-hui (2018) examines tourist perception of fog and haze in Xi'an (a world famous historical and cultural city in China). In this study, the tourists were categorized into three segments ("blunt type", "normal type" and "sensitive type") according to their perceptions of the fog and haze. Differences were obtained in terms of sociodemographic profiles and travel behaviour (before and during the trip). Tourists may not perceive the AQ conditions of the location they are visiting until they reach their home countries and feel the difference.

Other authors focussed on the tourist environmental risk perception and on the influence of this perception on present and future visits. Bohm and Pfister (2011) analyse traveller environmental risk perception in two tourism destinations with different environmental problems as follows: Australia (with ozone depletion) and Bangkok (with severe air pollution). Results show that travellers usually perceive lower risks than non-travellers, and that the decision to travel to environmentally afflicted destinations is related to people's anticipated emotional response. Becken et al. (2017) also reveals that, to American and Australian citizens, feelings towards the air (affective risk perceptions) also have a negative impact on intentions to visit China. Law and Cheung (2009) concluded this when analysing international visitor perception of $\mathrm{AQ}$ (both indoor and outdoor) in Hong Kong. Their findings reveal that the respondents generally do not perceive the $A Q$ in Hong Kong as a concern when they select this country as a tourism destination, but after their visit they considered the $A Q$ in Hong Kong worse than in their home countries. Moreover, the results also reveal that many of the respondents were willing to pay an additional departure tax to fund improvements in $A Q$.

3.7.1.2 Impact on well-being and quality of life. One set of studies (Bohm and Pfister, 2011; Hipp and Ogunseitan, 2011; Pant et al., 2018; Sato et al., 2016) analyses the impact of AQ on well-being and QOL. Environmental problems experienced during the trip may affect travellers' assessment of their QOL, as stated by Bohm and Pfister (2011) in a study based on Germans who travelled to environmentally afflicted destinations (Australia and Bangkok) and of Germans who did not travel. A study conducted in the California beaches by Hipp and Ogunseitan (2011), using objective and subjective measures of $A Q$, highlights the important impact of $A Q$ on some aspects of visitors' $Q O L$, through ordinal logistic models. The perceived $A Q$, measured using a scale from "very unhealthy" to "very healthy", has a significant positive influence on the perception of psychological restorativeness as a whole and four dimensions of this construct - fascination, coherence, compatibility and legibility. Moreover, visitors are much more likely to perceive a higher psychological restorativeness in days considered as healthy $A Q$, taking into account an objective measurement of ground-level ozone concentrations. This is noticed for restorativeness as a whole and to its five dimensions considered in the study - being away, fascination, coherence, compatibility and legibility.

The impact of the exposure to air pollutants perceived by tourists and their potential health risks was also a focus in some studies such as Pant et al. (2018) and Sato et al. (2016). The first study was carried out in Vietnam, concluding that the exposure of a tourist to air pollutants in Vietnam is lower than in cities in India and China. The second study was carried in China (Beijing) and confirmed the impact of short-term exposure to high concentrations of PM (PM 2.5 and PM 10) on tourist health, specifically on the cough reflex threshold, urge-to-cough and pulmonary function. Authors remark that a higher risk can 
exist in the case of unhealthy and health fragile groups (e.g. elderly, children and people with asthma or other pulmonary diseases).

3.7.1.3 Impact on visitors' satisfaction Only four studies (Agarwal et al., 2018; Peng and Xiao, 2018; Saura et al., 2018; Wu et al., 2018) examine the impact of $A Q$ on visitor satisfaction. Factors influencing Chinese satisfaction with international self-drive holidays were analysed in Wu et al. (2018). AQ is one of the factors analysed. Findings show that for the Chinese drive tourists, $A Q$ has a positive and significant effect on their overall travel satisfaction. Moreover, Peng and Xiao (2018) also observed that in the case of domestic tourists of Beijing, the perception of experience risk produced by smog could cause travel dissatisfaction. Furthermore, Agarwal et al. (2018) examine whether hotel review scores provided by guests travelling in Singapore and Hong Kong in three online platforms TripAdvisor.com, Agoda.com and Expedia.com - are influenced by haze episodes. Serious haze episodes showed to have a negative impact on online review scores, which reveals a decrease on guest satisfaction levels. Saura et al. (2018) analysed tweets of 25 Spanish hotels on social media, with the aim of investigating the experience of hotel guests. The authors try to identify environmental factors among comments grouped into negative and positive, according to guest feelings. Environmental factors related to atmospheric contamination emerge with considerable frequency, among negative and positive tweets. This means that these features are relevant for hotel guests and can trigger positive feelings when people perceive a good AQ. On the other hand, when contamination exists and there are risks of asthma and other breathing problems, negative feelings emerge.

3.7.1.4 Impact on destination image. Despite that, theoretically, $A Q$ is a relevant attribute to the competitiveness of tourism destinations, the research in this field is very scarce. Only the studies carried out by Becken et al. (2017) and Peng and Xiao (2018) investigate the impact of $A Q$ on destination image. The model developed by Becken et al. (2017) is tested among Americans and Australians, and results reveal that feelings towards the air (affective risk perceptions) have a negative impact on both the cognitive and affective image of China. However, no significant differences are detected on feelings towards the risk of $A Q$ between American and Australian citizens. Moreover, concerning China domestic tourists, the majority agree that smog has a negative influence on Beijing's image, as concluded by Peng and Xiao (2018).

3.7.2 Impact on global tourism demand. There are also studies that address the impact of $A Q$ on tourism but at the macro level. That is, not analysing the individual decisions of the tourist, but looking at the tourism industry of a country or region or a specific tourism attraction (such as a natural park). A consensual conclusion is that air pollution reduces the number of tourists (Anaman and Looi, 2000; Deng et al., 2017; Wang et al., 2018; Sajjad et al., 2014; Zhou et al., 2018; Liu et al., 2019; Keiser et al., 2018; Yan et al., 2019; Chen et al., 2017). For instance, Anaman and Looi (2000), using two different methodologies, estimated that 1997 and 1998 haze-related air pollution in Brunei caused about 3.75 or 28.70 per cent reduction in the number of tourists and that the total direct economic loss suffered by the tourism industry was estimated to be about $B \$ 1 \mathrm{~m}$ to $\mathrm{B} \$ 8 \mathrm{~m}$ (respectively, for each methodology). Furthermore, these negative economic losses and negative impacts on tourist demand are very reliant on the phases of business cycles (Chen et al., 2017). Another example of clear evidence of negative impacts of bad AQ on tourists, as well as on human health, is the study of Keiser et al. (2018), for the USA national parks. They found a strong negative relationship between ozone concentrations and park visitation.

The impact of $A Q$ on tourism can vary when different pollutants are analysed. For instance, Liu et al. (2019) concluded that carbon dioxide has no significant impact on tourism while PM 2.5 has a significant negative impact. The reason for this result may be that the effect of PM 2.5 on air is that its more perceptible compared to $\mathrm{CO}_{2}$ (colourless and odourless). Yan et al. (2019) concluded that $\mathrm{SO}_{2}$ has the largest impact on tourism demand, followed by $\mathrm{PM} 2.5, \mathrm{NO}_{2}$ and $\mathrm{PM} 10$, while $\mathrm{CO}$ (carbon monoxide) and $\mathrm{O}_{3}$ seem to have little influence. 
Another interesting result comes from Zhou et al. (2018), who reveal that the negative impact on tourism is higher when pollution increases. For low levels of pollution, there are almost no perceived impacts, but as $A Q$ further deteriorates, tourists become more alert to its adverse effect, and thus, the negative impact of air pollution occurs.

The impacts of $A Q$ can also be different between domestic and international tourists (Liu et al.,2019), overnight visitors and one day visitors (Poudyal et al., 2013), as well as visitors and local residents (Yan et al., 2019). Liu et al. (2019) concluded that for China, domestic tourists are more sensitive than international tourists. The reason may be that international visitors are not able to perceive the $A Q$ of China or have little or no information about this condition before travelling to the country. Poudyal et al. (2013) estimated elasticity for a national park in the USA, revealing that a programme aiming to improve the average visibility by 10 per cent $(5.5 \mathrm{~km})$ from the current level could result in an increase of about one million annual recreational visits. However, the increase would be higher for overnight visitors than for day visitors because the elasticity of tourism demand with respect to visibility was higher in overnight visitors. Yan et al. (2019) also estimated that the effect of pollutants is at least four times smaller on visitors than on local residents.

Time is also an important variable, as pollution worsens, the impact of pollution will last for a longer period and the degree of the impact in each time period will be more severe (Zhou et al., 2018). Some authors identify a delay effect in the impacts of $A Q$ on tourism demand (five days in the case of Wang et al. (2018) and one month in the case of Zhou et al. (2018). Poudyal et al. (2013) concluded that park visitations in a given month are significantly affected by the cumulative effect of the visibility condition in both the current and proceeding months.

Some authors have already indicated that the study of the impact of air pollution on tourism variables may be enriched with the introduction of some control variables such as tourism resource endowments, namely, the level of transport infrastructure, open-up degree, accommodation facilities (Deng et al., 2017) or disposable income level (Wang et al., 2018). Deng et al. (2017) also conclude that air pollution in nearby regions also affects local tourism, being the spillover effect (indirect effect) even larger than the direct effect.

\section{Conclusions}

A systematic review was performed to study the subject of impacts of $A Q$ on tourism demand, analysing the different methods and approaches used to assess these impacts and the results obtained. A total of 26 papers were identified, with the majority published in the past decade (88 per cent) and quite restricted/focussed to China and Southeast Asia regions.

The reduced number of studies analysing the impact of $A Q$ on tourism and the diversity of dimensions of $A Q$ or tourism demand considered in these studies, make it difficult to draw conclusions on this kind of impact. However, some trends are observable. Both research on global tourism demand and on individual perceptions reveal that $A Q$ tends to have a positive influence on tourism demand, with decreases in $A Q$ leading to decreases in tourism flows or to a lower likelihood of visiting certain destinations.

The studies reviewed confirm that nobody would like to travel to those places where the environment is severely polluted. Compared with other environmental pollution such as water and soil pollution, air pollution is much more visible and can be perceived more easily by the public, which justifies the high impact that it may have on tourism in a given destination. Special attention should be devoted to avoiding high levels of pollution and bad conditions regarding $A Q$, as the impact of $A Q$ on tourism tends to be higher when $A Q$ is significantly reduced.

The results and conclusions of the present study can contribute to tourism management in similar destinations around the world. Hereby, more attention should continue to be devoted to inspecting the influences of any changes in atmospheric conditions on the demand for tourism, as extreme weather events are becoming more intense and more frequent. 
Although some research studies have examined the negative impacts of air pollution on tourism, this important area of inquiry is still in its early stages and many critical issues have yet to be analysed and discussed. The most notable issues are how $A Q$ influences the seasonality of tourism demand, tourism experience, attractiveness and competitiveness of tourism industry; and how it influences the magnitude and nature of the economic impacts of tourism industry. There is further lack of studies, which relate $A Q$ impacts to population exposure (pollutant concentration multiplied by people and time). Therefore, more secondary data related to regional and national impacts of tourism activities has to be included into the analysis of the relationship between $A Q$ and tourism. As previously mentioned, China and Asiatic countries have been extensively analysed under this issue. However, little is known about other regions and nations around the world where $A Q$ levels are low or are significantly affected by high levels of air pollution.

Besides that, there is still a limited number of studies examining the role of $A Q$ in the attractiveness and competitiveness of tourism destinations, and the question about the effects of $A Q$ over tourism destination choices remains unanswered. Then, very little concern is devoted to good $A Q$ and how the $A Q$ index can become an important destination attribute influencing the attractiveness of tourism destinations.

Despite being a systematic literature review, this study has limitations that need to be addressed. The first is that the studies analysed, i.e. those focussed on the effects of outdoor $A Q$ on tourism, are very scarce. This partially results from the option to only include studies focussed on outdoor $A Q$. As $A Q$ is extremely linked to physical comfort and may have impacts on the tourist experience, future research should include studies on indoor $A Q$, providing the opportunity to strengthen the sample and to establish some comparisons between two different, but in a certain way, related matters.

Another limitation is the fact that most of the studies were focussed on Asian countries, with very few being conducted in other regions of the world. Although being an uncontrolled issue, there is an opportunity for future studies to be developed, helping to understand if the findings obtained in Asian countries are aligned and coherent with other regions, namely, in a context where environmental awareness is a growing phenomenon.

Finally, the option to only include papers in English can also be pointed out as a limitation, namely, because they may not be representative of all the evidence on the topic in analysis. Therefore, future research should be extended to included literature published in other languages.

Considering the great need of carrying out more studies, especially in other regions of the world beyond Asian countries, to ensure a sustainable development of tourism in the future, a wide plethora of methodological approaches may be adopted. As already mentioned, secondary data should be further explored. Moreover, mixed methodological approaches, including both quantitative and qualitative methods, should be privileged in further research to obtain a deeper knowledge of how $A Q$ affects tourism demand and, consequently, the competitiveness of tourism destinations. Considering the environmental changes that have been occurring and that will take place in the future, longitudinal studies are also highly relevant to assess how the impact of $A Q$ on tourism demand is changing and what kind of strategies should be designed to ensure sustainable development. The ongoing Portuguese research project ARTUR (http://projeto-artur.web.ua.pt) will address some of these concerns and its outcomes may help to increase the knowledge on both the environmental and tourism sectors, promoting both $A Q$ protection and tourism sustainability.

\section{Acknowledgements}

Thanks are due for the financial support to FCT/MCTES through national funds, and the cofunding by the FEDER, within the PT2020 Partnership Agreement and Compete 2020, for the ARTUR project (POCI-01-0145-FEDER-029374) and CESAM (UID/AMB/50017 - POCI01-0145-FEDER-007638). 


\section{References}

Agarwal, S., Wang, L. and Yang, Y. (2018), "Blessing in disguise? Environmental shocks and performance enhancement", ShanghaiTech SEM Working Paper No. 2018-012, November. available at: http://ssrn.com/abstract=1330752 (accessed 24 January 2019).

Anaman, K. and Looi, C. (2000), "Economic impact of haze-related air pollution on the tourism industry in Brunei Darussalam”, Economic Analysis and Policy, Vol. 30 No. 2, pp. 133-143.

Becken, S., Jin, X., Zhang, C. and Gao, J. (2017), "Urban air pollution in China: destination image and risk perceptions", Journal of Sustainable Tourism, Vol. 25 No. 1, pp. 130-147.

Bohm, G. and Pfister, H.-R. (2011), "Tourism in the face of environmental risks: sunbathing under the ozone hole, and strolling through polluted air", Scandinavian Journal of Hospitality and Tourism, Vol. 11 No. 3, pp. 250-267.

Centobelli, P. and Ndou, V. (2019), "Managing customer knowledge through the use of big data analytics in tourism research", Current Issues in Tourism, Vol. 1, pp. 1-22.

Chen, C.-M., Lin, Y.-L. and Hsu, C.-L. (2017), "Does air pollution drive away tourists? A case study of the sun moon lake national scenic area, Taiwan", Transportation Research Part D: Transport and Environment, Vol. 53, pp. 398-402.

Comerio, N. and Strozzi, F. (2019), "Tourism and its economic impact: a literature review using bibliometric tools", Tourism Economics, Vol. 25 No. 1, pp. 109-131.

Costa, S., Ferreira, J., Silveira, C., Costa, C., Lopes, D., Relvas, H., Borrego, C., Roebeling, P., Miranda, A.I. and Paulo Teixeira, J. (2014), "Integrating health on air quality assessment - review report on health risks of two major European outdoor air pollutants: $\mathrm{PM}$ and $\mathrm{NO}_{2}$ ", Journal of Toxicology and Environmental Health Part B Critical Review, Vol. 17 No. 6, pp. 307-340.

Dann, D., Teubner, T. and Weinhardt, C. (2019), "Poster child and guinea pig - insights from a structured literature review on Airbnb", International Journal of Contemporary Hospitality Management, Vol. 31 No. 1, pp. 427-473.

Deng, T., Xin, L. and Mulan, M. (2017), "Evaluating impact of air pollution on China's inbound tourism industry: a spatial econometric approach", Asia Pacific Journal of Tourism Research, Vol. 22 No. 7 , pp. 771-780

Hill, L.B., Halstead, J.M., Stevens, T.H. and Kimball, K.D. (2000), "Visitor perceptions and valuation of visibility in the great Gulf wilderness, New Hampshire", USDA Forest Service Proceedings, Vol. 5, pp. 304-311.

Hipp, J.A. and Ogunseitan, O.A. (2011), "Effect of environmental conditions on perceived psychological restorativeness of coastal parks", Journal of Environmental Psychology, Vol. 31 No. 4, pp. 421-429.

Jun-Hui, Y. (2018), "Research on the tourists' type and behavior based on the fog and haze perception: taking X''an as a case", in Weng, C.H. \& Weerasinghe, R. (Eds), Proceedings of 3rd International Conference on Advances in Energy and Environment Research, Vol. 53, Les Ulis: E3S Web of Conferences.

Keiser, D., Lade, G. and Rudik, I. (2018), "Air pollution and visitation at US national parks", Science Advances, Vol. 4 No. 7, eaat1613.

Law, R. and Cheung, C. (2009), "Air quality in Hong Kong: a study of the perception of international visitors", Journal of Sustainable Tourism, Vol. 15 No. 4, pp. 390-401.

Liu, J., Pan, H. and Zheng, S. (2019), "Tourism development, environment and policies: differences between domestic and international tourists", Sustainability, Vol. 11 No. 5, pp. 1390-1405

Nejati, M., Mohamed, B. and Omar, S.I. (2015), "The influence of perceived environmental impacts of tourism on the perceived importance of sustainable tourism", e-Review of Tourism Research, Vol. 12 Nos 1/2, pp. 99-114.

Pant, P., Huynh, W. and Peltier, R. (2018), "Exposure to air pollutants in Vietnam: assessing potential risk for tourists", Journal of Environmental Sciences, Vol. 73, pp. 147-154.

Peng, J. and Xiao, H. (2018), "How does smog influence domestic tourism in China? A case study of Beijing", Asia Pacific Journal of Tourism Research, Vol. 23 No. 12, pp. 1115-1128. 
Poudyal, N.C., Paudel, B. and Green, G.T. (2013), "Estimating the impact of impaired visibility on the demand for visits to national parks", Tourism Economics, Vol. 19 No. 2, pp. 433-452.

Ritchie, J.R.B. and Crouch, G.I. (2003), The Competitive Destination? A Sustainable Tourism Perspective, CABI Publishing, Cambridge, MA.

Rizzi, L.I., De La Maza, C., Cifuentes, L.A. and Gómez, J. (2014), "Valuing air quality impacts using stated choice analysis: trading off visibility against morbidity effects", Journal of Environmental Management, Vol. 146, pp. 470-480.

Rossello-Nadal, J. (2014), "How to evaluate the effects of climate change on tourism", Tourism Management, Vol. 42, pp. 334-340.

Saenz-de-Miera, O. and Rosselló, J. (2013), "Tropospheric ozone, air pollution and tourism: a case study of Mallorca”, Journal of Sustainable Tourism, Vol. 21 No. 8, pp. 1232-1243.

Sajjad, F., Noreen, U. and Zaman, K. (2014), "Climate change and air pollution jointly creating nightmare for tourism industry", Environmental Science and Pollution Research, Vol. 21 No. 21, pp. 12403-12418.

Sato, R., Gui, P., Ito, K. and Kohzuki Ebihara, S. (2016), "effect of Short-term exposure to high particulate levels on cough reflex sensitivity in healthy tourists: a pilot study", The Open Respiratory Medicine Journal, Vol. 10 No. 1, pp. 96-104.

Saura, J.R., Palos-Sanchez, P. and Martin, M.A.R. (2018), "Attitudes expressed in online comments about environmental factors in the tourism sector: an exploratory study", International Journal of Environmental Research and Public Health, Vol. 15 No. 3, p. 553.

Seaton, A., Godden, D., MacNee, W. and Donaldson, K. (1995), "Particulate air pollution and acute health effects", Lancet (London, England)), Vol. 345 No. 8943, pp. 176-178.

Wang, L., Fang, B. and Law, R. (2018), "Effect of air quality in the place of origin on outbound tourism demand: disposable income as a moderator", Tourism Management, Vol. 68, pp. 152-161.

World Health Organization [WHO] (2017), World Health Statistics 2018: monitoring Health for the SDGs, Sustainable Development Goals, World Health Organization, Geneva.

Wu, M.-Y., Pearce, P.L. and Li, Q. (2018), "Chinese behind the wheel: factors affecting their satisfaction with international self-drive holidays", Journal of Destination Marketing \& Management, Vol. 9, pp. 12-19.

Yan, L., Duarte, F., Wand, D., Zheng, S. and Ratti, C. (2019), "Exploring the effect of air pollution on social activity in China using geotagged social media check-in data", Cities, Vol. 91, pp. 116-125.

Zajchowski, C.A.B., Brownlee, M.T.J. and Rose, J. (2018), "Air quality and the visitor experience in parks and protected areas", Tourism Geographies, Vol. 1, doi: 10.1080/14616688.2018.1522546.

Zhang, A., Zhong, L., Xu, Y., Wang, H. and Dang, L. (2015), "Tourists' perception of haze pollution and the potential impacts on travel: reshaping the features of tourism seasonality in Beijing, China", Sustainability, Vol. 7 No. 3, pp. 2397-2414.

Zhou, B., Qu, H., Du, X. and Liu, F. (2018), "Air quality and inbound tourism in China", Tourism Analysis, Vol. 23 No. 1, pp. 159-164.

Zhu, R. (2018), "Analysis on the impact of haze on Beijing residents' traveling intention and DecisionMaking", IOP Conference Series: Materials Science and Engineering, Vol. 394.

\section{Further reading}

Law, R. and Cheung, C. (1998), "Prospects of the Hong Kong tourism industry", Hospitality Review, Vol. 16 No. 2, pp. 39-51.

Saenz-de-Miera, O. and Rosselló, J. (2014), "Modeling tourism impacts on air pollution: the case study of PM10 in Mallorca", Tourism Management, Vol. 40, pp. 273-281.

\section{About the authors}

Celeste Eusébio is an Assistant Professor of Tourism and a researcher at the GOVCOPP Research Unit at the University of Aveiro (UA) (Portugal). She holds a degree in Tourism Management and Planning from the UA (1995), a Master in Economics from the University 
of Coimbra (1998) and a doctoral degree in tourism, also from the UA (2006). Her research interests include tourism economics, tourism and sustainable development, tourism forecasts and consumer behaviour in tourism. Celeste Eusébio is the corresponding author and can be contacted at: celeste.eusebio@ua.pt

Maria João Carneiro is Assistant Professor of Tourism at the University of Aveiro (UA) (in Portugal) and researcher at the Governance, Competitiveness and Public Policy (GOVCOPP) research unit at this University. She holds a degree in Tourism Management and Planning from UA, an MBA from New University of Lisbon and a PhD in tourism from UA. She has published papers in several journals and conference proceedings, and has also presented several works in conferences and seminars. Her research interests are competitiveness of tourism destinations, consumer behaviour in tourism and destination marketing.

Mara Madaleno is Assistant Professor at the University of Aveiro (UA). Member of the Research Unit on Governance, Competitiveness and Public Policies (GOVCOPP), currently lectures Finance and Economics at the undergraduate, graduate MSc and PhD levels at the Department of Economics, Management, Industrial Engineering and Tourism. She is a coauthor of scientific articles in peer-reviewed reference journals, books and book chapters in the areas of energy economics, finance and economics. Director of the Master in Economics (branches of Finance and Company Economics) at the DEGEIT and vicedirector of the master in sustainable energy systems, both in $\cup A$.

Margarita Robaina holds a PhD in Economics, a Master's in Business Economics and a degree in Economics from the University of Aveiro (UA). She is a member of the Governance, Competitiveness and Public Policy Research Unit, in the Competitiveness, Innovation and Sustainability group. Its areas of interest are Energy Economics, Environmental and Natural Resources Economics and Energy and Environmental Policy. She is an Assistant Professor in the Department of Economics, Management, Industrial Engineering and Tourism at the UA since 2011 and is currently a member of the Executive Committee of the Department. Margarita has several publications with scientific arbitration and has participated in several conferences and projects.

Vitor Rodrigues is a research fellow at the Department of Economics, Management, Industrial Engineering and Tourism, University of Aveiro (UA). With a Master in Tourism Management and Planning and a degree in Tourism from the UA, his research work has been focussed on Chinese Outbound Tourism, Meetings Industry and Tourism Governance, counting several scientific works as author and co-author.

Michael Russo is a research fellow at the Department of Environment and Planning, University of Aveiro. With a BSc in Environmental Engineering (2014) and a MSc in sustainable energy systems (2016), he is a member of the GEMAC research group working in emissions modelling and regional air quality modelling.

Hélder Relvas holds a PhD in Environmental Sciences and Engineering. The focus of his research work is air quality management using neural networks and Integrated Assessment Models to develop plans and measures to improve air quality. He is already author of more than 10 scientific papers and have participated in several national projects and international research projects.

Carla Gama has a PhD in Environmental Sciences and Engineering. The focus of her research work is on the long-range transport of mineral dust from North Africa, its composition and deposition over the ocean. She has been participating in European and National research projects and collaborating with the Portuguese Environmental Agency regarding the air quality forecast system over Portugal.

Myriam Lopes is an Assistant Professor of Environmental Engineering at the University of Aveiro (UA). She holds a PhD in Environmental Science from the UA (2007), a Master in Atmospheric pollution (2003) and a degree in Environmental Engineering. She is a researcher and vice-coordinator of CESAM - Centre for Environment and Marine Studies - associated laboratory. Her researcher topics cover air quality management and 
climate change mitigation and adaptation strategies, with emphasis on urbanized areas, including heath impacts, urban metabolism and sustainability. She was involved in several national and international research projects, as well as technical consultancy projects for society.

Vânia Seixas holds a PhD Student Programme on Environmental Sciences and Engineering, Licensed degree in Environmental and Natural Resources Engineering (preBologna treaty) at the University of Trás-os-Montes and Alto Douro (UTAD) in 2008. Master's degree in Environmental Engineering in 2014. Participation in more than 10 technical-scientific events; Presented four oral communications, two of them in international congresses. Co-author of one book published by Principia Editora and of four technicscientific reports. Is also co-author, as first author, of two scientific articles in indexed proceedings. Actuality she has a scholarship at the University of Aveiro.

Carlos Borrego is Emeritus Full Professor of Environmental Engineering at the University of Aveiro (UA). During more than 40 years working on environmental problems, he is representing Portugal in international scientific organizations, in committees for research and evaluation of environmental strategy and sustainable development. He was Minister of Environment (XI and XII Governments), Vice-Rector for Research in the UA, Director of the Department of Environment and Planning, National Delegate to the EU Research and Innovation Framework Programs and Director of IDAD-Institute for Environment and Development, the interface unit of University of Aveiro for cooperation with the Society.

Alexandra Monteiro holds a PhD in Environmental Science from the University of Aveiro (UA) (2007), a Master in Atmospheric pollution (2003) and a degree in Chemical Engineering, from the University of Porto in 1996. She was Assistant Professor since 2008 and is presently a Principal Researcher at UA, belonging to the CESAM - Centre for Environment and Marine Studies - associated laboratory. She has more than $60 \mathrm{SCl}$ papers and her main research interests include gaseous and aerosol emission pollutants, in particular shipping emissions, air quality modelling and its impacts on climate and human health.

For instructions on how to order reprints of this article, please visit our website: www.emeraldgrouppublishing.com/licensing/reprints.htm

Or contact us for further details: permissions@emeraldinsight.com 